\title{
LIQUEFIED WOOD AS A PARTIAL SUBSTITUTE OF MELAMINE-UREA- FORMALDEHYDE AND UREA-FORMALDEHYDE RESINS
}

\author{
Bruno Esteves ${ }^{1,2, \wedge}$, Joũo Martins ${ }^{3}$, Jorge Martins ${ }^{1,4}$, Luísa Cruz-Lopes $^{1,2}$, \\ José Vicente ${ }^{1,2}$, Idalina Domingos ${ }^{1,2}$
}

\begin{abstract}
Maritime pine (Pinus pinaster) sawdust was used to produce liquefied wood by the polyhydric method with acid catalysis. The process was optimized to produce the highest amount of liquefied wood. Wood liquefied at $160^{\circ} \mathrm{C}$ for $90 \mathrm{~min}$ was used in the adhesion tests. The bond strength of veneer glued with ureaformaldehyde and melamine-urea-formaldehyde resins and several mixtures of liquefied wood with ureaformaldehyde and melamine-urea-formaldehyde wasevaluated by automated bonding evaluation system.

With the increase in liquefied wood content the bond strength decreased. Nevertheless for $20 \%$ liquefied wood the reduction of internal bond strength is relatively small and still within the minimum standards required. When $70 \%$ of liquefied wood is employed there is a significant decrease in bond strength.

In conclusion it is possible to use a small amount of maritime pine sawdust liquefied wood as a partial substitute of urea-formaldehyde and melamine-urea-formaldehyde resins in the particleboard production, thus decreasing the formaldehyde content.
\end{abstract}

Keywords: Automated bonding evaluation system, liquefied wood, particleboard, Pinus pinaster, resin.

\section{INTRODUCTION}

Wood liquefaction is usually done at high pressure and temperature. Recently due to the lack of oil derived products there have been several studies on liquefaction processes using moderate temperatures and a catalyst. The main liquefaction agents are phenol (Zhang et al. 2007, Lin et al. 2014) with a base or acid catalyst, polyhydric alcohols usually with an acid catalyst (Hrastnik et al. 2013) and also cyclic carbonates (Xie and Chen 2005), ionic liquids and dibasic esters. According to the liquefaction process different resins can be produced. When liquefaction is done with phenol, phenolic resins can be produced. Pan et al. (2009) used liquefied wood with phenol an acid catalyst to prepare phenolic Novolac type resins while Hassan et al. (2009) produced Resol type resins. Alma et al. (1998) and Zhang et al. (2005) produced the same type of resins but using alkali catalysts. Using polyhydric alcohols as liquefaction agents produces different kinds of resins. Lee and Lin (2008) used liquefied wood to produce a polyurethane adhesive. Also epoxy resins were prepared by Kobaiashi et al. (2000) from liquefied wood with polyhydric alcohols. Mansouri et al. (2007) studied the possibility of using liquefied wood as lignin-based wood panel adhesives without formaldehyde. The adhesives yielded a bending strength enough to pass relevant international standard specifications for exterior-grade panels and also showed sufficient reactivity to yield panels in press times comparable to those of formaldehyde-based commercial adhesives. The bond performance of specimens of beech wood, bonded with an adhesive mixture made of liquefied wood and phenolic resin, was investigated by Ugovsek et al. (2010). The shear strength increased when replacing $25 \%$ of the phenol-formaldehyde by liquefied wood, but decreased when immersing or boiling the specimens in water. So for non-structural applications

\footnotetext{
${ }^{1}$ Polytechnic Institute of Viseu, Viseu, Portugal.

${ }^{2}$ Centre for the Study of Education, Technologies and Health (CI\&DETS). Viseu. Portugal

${ }^{3}$ Student in Polytechnic Institute of Viseu. Viseu. Portugal

${ }^{4}$ Lepae, Laboratory for Process, Environmental and Energy Engineering, Faculdade de Engenharia, Universidade do Porto, Porto, Portugal

^Corresponding author: bruno@demad.estv.ipv.pt

Received: 24.01.2014 Accepted: 30.06 .2014
} 
in dry conditions, up to $25 \%$ of the synthetic phenol-formaldehyde resins could be replaced by liquefied wood with a satisfactory bond. Kunaver et al. (2010) studied the possibility to partially replace resins UF, MF and MUF for liquefied wood for the production of panels and concluded that it would be possible to replace up to $50 \%$ of the minimum characteristics required maintaining resins for this type of panels. The main goal of this research was to use liquefied pine sawdust prepared by the polyhydric alcohol process as a partial substitute of UF and MUF resins in particleboard production. The optimization of temperature, time and amount of polyhydric alcohol to obtain the higher liquefaction percentage was presented before by the authors in (Martins et al. 2013). The results show that the higher the temperature, the greater the percentage of liquefaction. At the same temperature the percentage increases with the liquefaction treatment time according to a logarithmic curve approximately until it reaches a maximum and then decreases, possibly due to condensation reactions of liquefaction products. The maximum liquefaction was obtained after $30 \mathrm{~min}$ at $180^{\circ} \mathrm{C}$ (about $80 \%$ ) and $60 \mathrm{~min}$ at $160^{\circ} \mathrm{C}$ (about $70 \%$ ). It was found that the ratio of wood/ ethylene glycol influenced the percentage of liquefaction that ranged between $62 \%$ and $88 \%$ and the ratio which showed best results was 1: 6 .

\section{EXPERIMENTAL}

\section{Wood Liquefaction reaction}

Maritime pine (Pinus PinasterAit) sawdust generated in the circular saw from a local carpentry was used in the tests. The sample was sieved and the 40-60 Mesh fraction was selected for the tests. Ethylene glycol (EG) was used as solvent and Sulfuric Acid (SA) as catalyst. Four parts of EG were used for each part of Pinus pinaster dust in dry state adding 3\% SA (based on the EG mass). The ratio between EG and wood was optimized before to achieve the highest liquefaction possible (Martins et al. 2013). The mixture was placed in a Parr glass $600 \mathrm{ml}$ LKT PED reactor (Figure 1) with double jacket with automatic stirrer at $\pm 70 \mathrm{rpm}$.

The liquefaction reaction was done at $160^{\circ} \mathrm{C}$ (temperature of the oil in the jacket) for $90 \mathrm{~min}$. The liquefaction time was optimized to obtain the highest liquefaction (Martins et al. 2013). The EG+SA+Wood were inserted inside the reactor when the oil achieved the desired temperature.

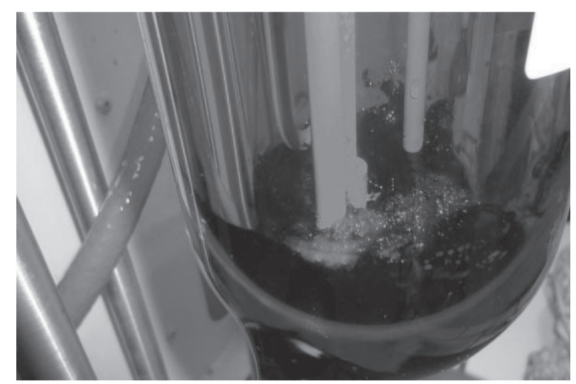

Figure 1. Liquefaction reactor.

After the reaction a mixture of dioxane and water at 4:1 ratio was used to solubilize the liquefied wood. A pump and a Buckner Funnel with a paper filter were used to separate the solid residues that resulted from the liquefaction. This allowed us to determine the liquefaction percentage that was calculated using the following formula:

$$
\text { Liquefaction percentage }(\%)=\left(1-\frac{\text { Massofresidue }(g)}{\text { Massofdrywood }(g)}\right) \times 100
$$

The water and dioxane were evaporated using a Rotary evaporator by using reduced pressure, $700 \mathrm{mmHg}$ provided by a vacuum pump. 


\section{Determination of Gel time}

For determination of the adhesive Gel time, different ratios between the liquefied wood and adhesive were tested, 9:1, 8:2, 7:3, 6:4, 5:5, for a total mass of $10 \mathrm{~g}$. The mixture was stirred with a glass rod until the Gel becomes apparent.

\section{Determination of bond strength by ABES}

Wood liquefied at $160^{\circ} \mathrm{C}$ for $90 \mathrm{~min}$ was used in the tests. The bond strength of veneer glued with ureaformaldehyde resin (UF), melamine-urea-formaldehyde resin (MUF) and several mixtures of Liquefied wood (LW) with UF and MUF were evaluated using ABES (Automated Bonding Evaluation System) equipment. Two beech veneer strips with $0,5 \mathrm{~mm}$ thick, $20 \mathrm{~mm}$ wide and $117 \mathrm{~mm}$ in length were used. The resins were prepared adding to the MUF resin, LW and ammonium sulphate (as catalyst). For each test $6,7 \mathrm{mg}$ of the mixture were used to glue an overlapping area of $100 \mathrm{~mm}^{2}$. ABES gives the force, in $\mathrm{N}$, necessary to break the glue line. The bonding strength (BS) was determined by the following formula.

$$
\text { Bonding strength }\left(\mathrm{N} / \mathrm{mm}^{2}\right) \text { or } \mathrm{MPa}=\left(\frac{\operatorname{Force}(\mathrm{N})}{\text { Overlappingarea }\left(\mathrm{mm}^{2}\right)}\right)
$$

Tests were made for 20,30, 50,100,150,200,350 and 600 seconds to allow the analysis of the different phases of deformation curve. Different blends of UF/LW and MUF/LW were tested.

\section{RESULTS AND DISCUSSION}

\section{Gel time}

Gel time for the mixtures of UF resins and wood liquefied at $160^{\circ} \mathrm{C}$ and $180^{\circ} \mathrm{C}$ was similar (Figure 2) for both temperatures. The Gel time decreased initially, from 600 s to 100 s with increased liquefied wood ratio until it reaches the 5:5 ratio. Then remained constant until 8:2 ratio is achieved and then increase again. The Geltime of Urea-formaldehyde resins (UF) occurs at $50-150 \mathrm{~s}$ at $100^{\circ} \mathrm{C}$ in the presence of a catalyst such as ammonium sulphate, but it is also possible using an acid catalyst such as sulfuric acid. Since liquefied wood has about $3 \%$ sulfuric acid, the initial decrease of Gel time is justified by the fact that the increase of acid has a higher effect than the increase in liquefied wood content. With a ratio higher than $8: 2$, the content of liquefied wood no longer allowed a correct gelification of the resin. A similar increase was obtained by Kunaver et al. (2010).

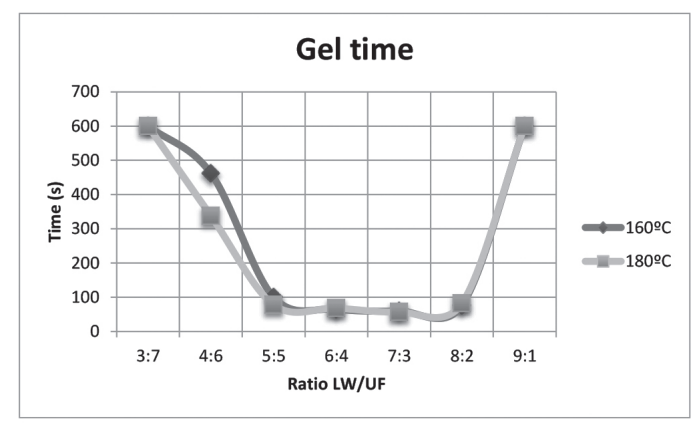

Figure 2. Gel time of mixtures of UF resin with liquefied wood at $160^{\circ} \mathrm{C}$ and $180^{\circ} \mathrm{C}$. 


\section{Neutralization}

Liquefied wood is highly acidic due, not only, to the sulphuric acid used as a catalyst but also to the acidic nature of most of the wood components. Since the acids acts as catalyst on the UF resins cure, tests were made to estimate the impact of neutralizing liquefied wood before mixing it with the resin. In figure 3 we can see the determination of bond strength by ABES for a resin resulting by mixing UF-LW (50:50), neutralized and non-neutralized and cured at $115^{\circ} \mathrm{C}$.

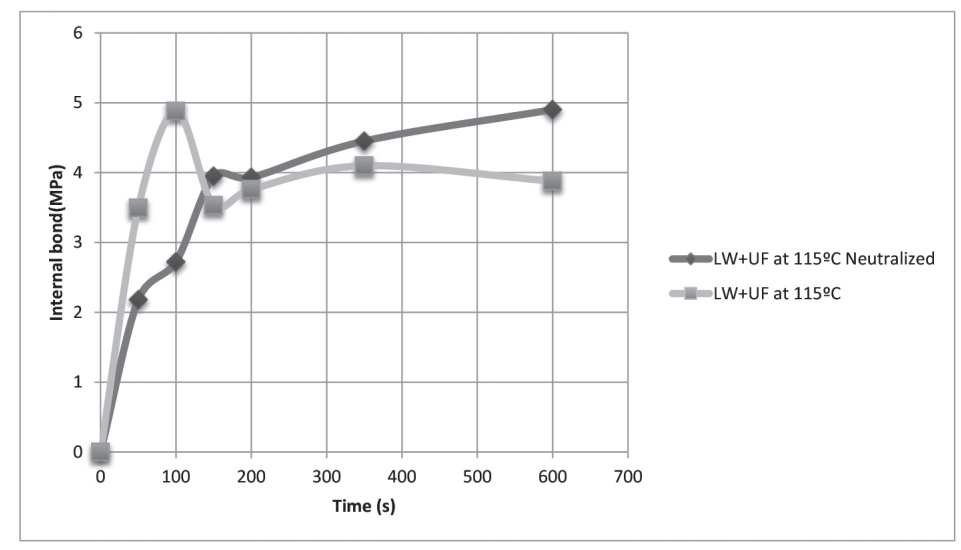

Figure 3. Bond strength of mixtures of liquefied wood not neutralized (LW) and neutralized (LWN) with a urea-formaldehyde resin (UF).

The bond strength of LW-UF resin at 600 s was about $4 \mathrm{MPa}$. However the maximum (5 MPa) was obtained at about $100 \mathrm{~s}$ which is next to the $80 \mathrm{~s}\left(100^{\circ} \mathrm{C}\right)$ used by the industry. Using the neutralized resin the slope of the linear zone was smaller and the maximum bond strength was also slightly lower although at $600 \mathrm{~s}$ has been higher $(4,5 \mathrm{MPa})$, which means it took longer to activate but the final results were similar.

\section{Pressing temperature}

In figure 4 we can see the ABES curve for a MUF resin pressed at $105^{\circ} \mathrm{C}$ and $115^{\circ} \mathrm{C}$. In accordance to Heineman (2004) and Ferra et al. (2011) the curve has three different stages, an initial delay attributed to the loss of energy due to water evaporation, a second nearly linear stage due to the polymerization reaction by chain-extension and cross-linking processes of the adhesive systems and a last stage is where the curves stabilize reaching maximum values. The initial stage is not shown in these figures because the first point was taken only at $50 \mathrm{~s}$ and by that time the initial delay had already occurred. The second, almost linear stage can be seen until around 100-150s for MUF-LW resin at both temperatures. The main difference observed is that at a higher temperature the curves have a higher slope in the linear stage. With longer pressing times the bond strength is similar for both temperatures. 


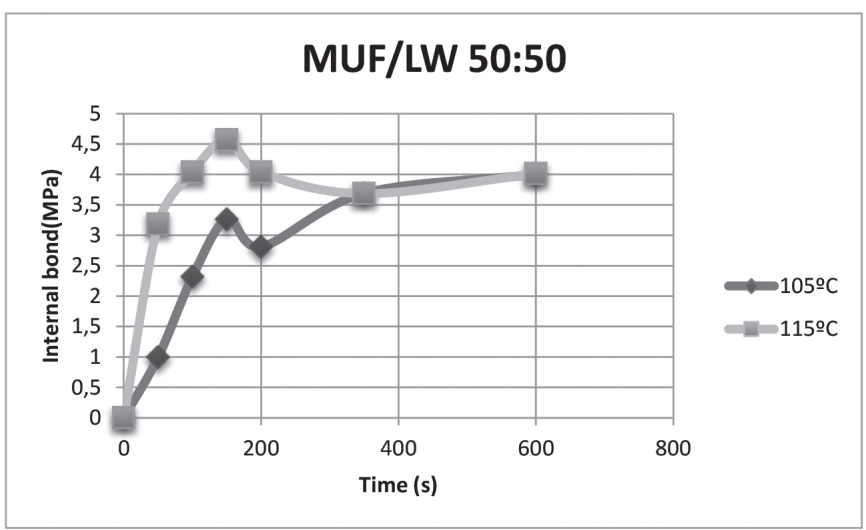

Figure 4. Bond strength determined by ABES for MUF-LW 50:50 at $105^{\circ} \mathrm{C}$ and $115^{\circ} \mathrm{C}$.

\section{Amount of liquefied wood}

Figure 5 shows the bond strength of MUF and MUF-LW resins determined by ABES. MUF resin presented the best results reaching a bondstrength of about $6 \mathrm{MPa}$ at $105^{\circ} \mathrm{C}$ and a little lower $5 \mathrm{MPa}$ at $115^{\circ} \mathrm{C}$. The maximum was obtained at about $100 \mathrm{~s}$ which is near the $80 \mathrm{~s}\left(\right.$ at $\left.100^{\circ} \mathrm{C}\right)$ used by the particleboard industry. With the increase in liquefied wood content bond strength decreased as expected. Nevertheless for $115^{\circ} \mathrm{C}$ and 100 s the bond strength reached around $4 \mathrm{MPa}$ for MUF-LW with $20 \%$ of liquefied wood. Comparing to MUF resin MUF-LW (20\%) had about $30 \%$ of bond strength decrease. At higher temperature $\left(115^{\circ} \mathrm{C}\right)$ the bond strength decreased less for $100-150$ s reaching a maximum of around $4,5 \mathrm{MPa}$. The mixture MUF-LW with $50 \%$ liquefied wood presented lower bond strength for $105^{\circ} \mathrm{C}$ pressing temperature. The maximum bond strength 3,2 MPa was almost half of the bond strength of the pure resin $(6 \mathrm{MPa})$. For $115^{\circ} \mathrm{C}$ however the decrease was lower. When $70 \%$ of liquefied wood is employed there is a significant decrease in bond strength for both temperatures with a maximum of about $2 \mathrm{MPa}$ at $115^{\circ} \mathrm{C}$ and a little lower for $105^{\circ} \mathrm{C}$. 

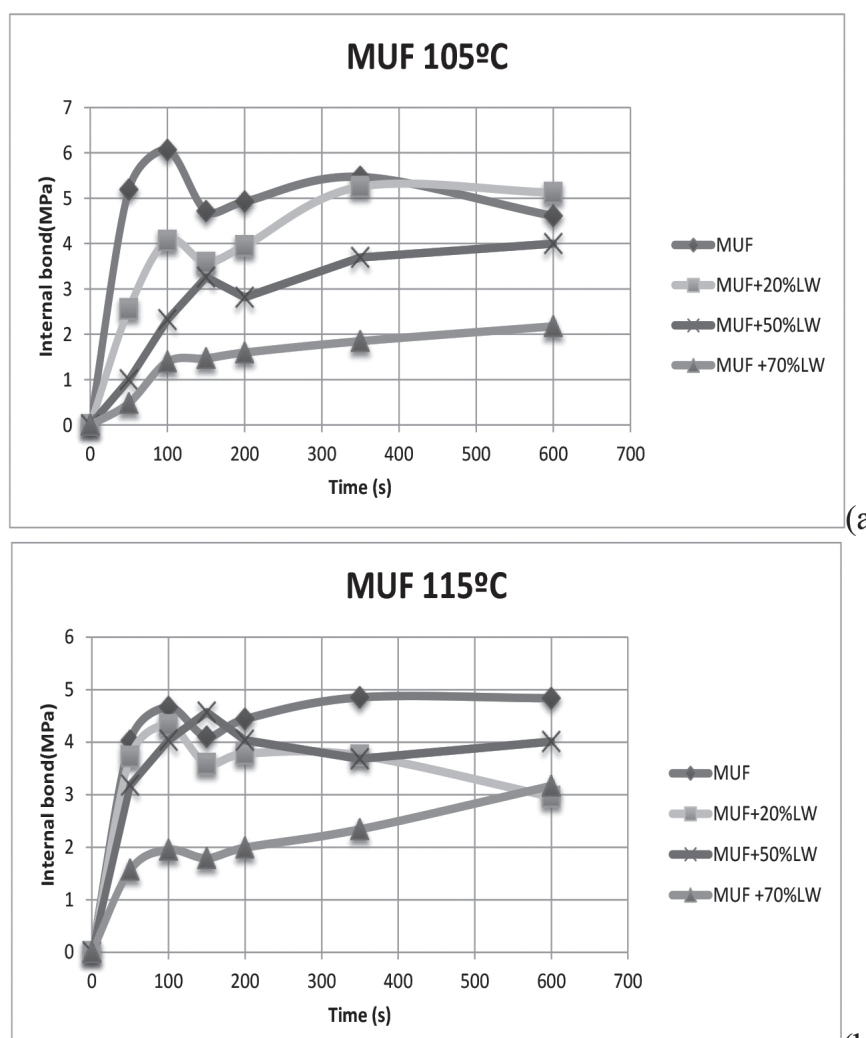

(a)

(b)

Figure 5. Internal bond strength determined by ABES for MUF and MUF-LW resins at $105^{\circ} \mathrm{C}(\mathrm{a})$ and $115^{\circ} \mathrm{C}(\mathrm{b})$.

When UF resins are used rather than MUF resins, the results are similar. Figure 6 shows the bond strength of UF and UF-LW resins determined by ABES. The main different is that MUF resins have somewhat higher bond strength than UF resins which have maximum bond strength around 4,5MPa. This also affects the mixtures of UF resins with liquefied wood which present smaller bond strength than the mixtures with MUF resin. With $20 \%$ liquefied wood the bond strength reduced about $33 \%$ and $13 \%$ for pressing temperatures of $105^{\circ} \mathrm{C}$ and $115^{\circ} \mathrm{C}$. For $70 \%$ of liquefied wood the reduction is higher attaining a $66 \%$ and $62 \%$ for $105^{\circ} \mathrm{C}$ and $115^{\circ} \mathrm{C}$ respectively. 


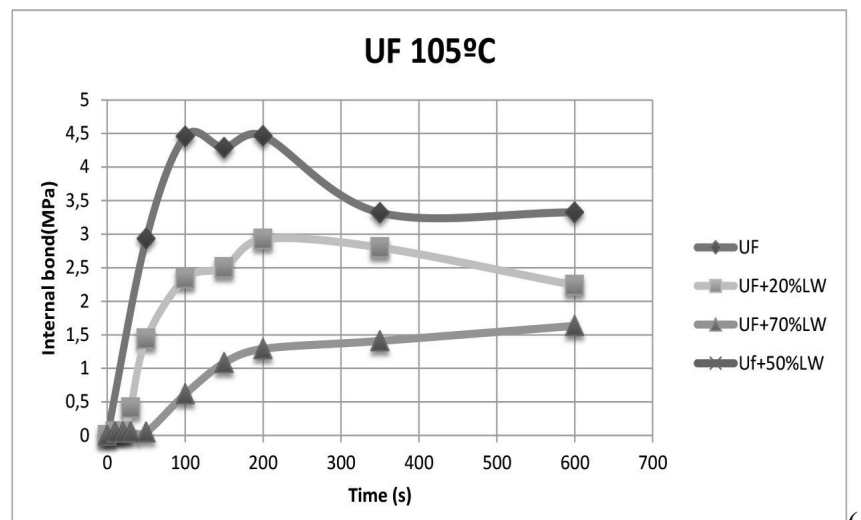

(a)

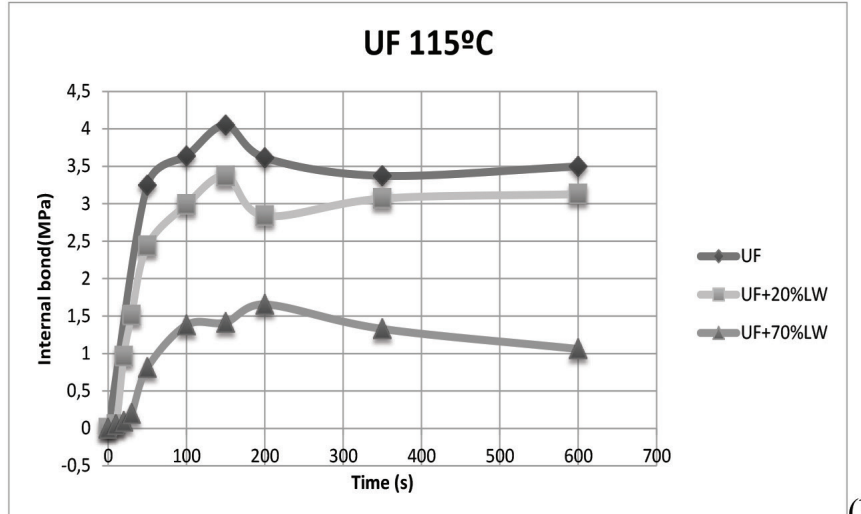

(b)

Figure 6. Bond strength determined by ABES for UF and UF-LW resins at $105^{\circ} \mathrm{C}$ (a) and $115^{\circ} \mathrm{C}(\mathrm{b})$.

\section{CONCLUSIONS}

With the increase in the percentage of LW there is a decrease in the Gel time until it reaches the ratio $5: 5$ and remained until a ratio of $8: 2$, increasing afterwards. The neutralized resin reacted slower but with similar maximum bond strength. With the increase in LW content bond strength decreased as expected. With $20 \% \mathrm{LW}$ the reduction of bond strength is relatively small and still within the minimum standards required but when $70 \%$ of LW is employed there is a significant decrease in bond strength. In conclusion it is possible to use a small amount of maritime pine sawdust liquefied wood as a partial substitute of UF and MUF resin in the particleboard production, thus decreasing the formaldehyde content.

\section{ACKNOWLEDGMENTS}

The authors are grateful for the support of the Portuguese Foundation for Science and Technology (ref. PEst-OE/CED/UI4016/2011) and the Centre for Studies in Education, Technologies and Health. 


\section{REFERENCES}

Alma, M.H.; Yoshioka, M.; Yao, Y.; Shiraishi, N. 1998. Preparation of sulfuric acid-catalyzed phenolated wood resin. Wood Sci Technol 32:297-308.

Ferra, J.M.M.; Ohlmeyer, M.; Mendes, A.M.; Costa, M.; Carvalho, L.; Magalhães, F. 2011. Evaluation of urea-formaldehyde adhesives performance by recently developed mechanical tests. International Journal of Adhesion \& Adhesives 31:127-134.

Hassan, E.B.; Kim, M.; Wa, H. 2009. Phenol-formaldehyde-type resins made from phenol-liquefied wood for the bonding of particleboard. J Appl Polym Sci 112:1436-43.

Heinemann, C. 2004. Characterization of the curing process of adhesives in wood-particle matrices by evaluation of mechanical and chemical kinetics. Hamburg: Institute for Wood Technology, University of Hamburg.

Hrastnik, D.; Budija, F.; Humar, M.; Petrič, M. 2013. Influence of liquefied and CCB containing liquefied wood on growth of wood decay fungi. Maderas. Ciencia y tecnología, 15(1): 105-118.

Kobayashi, M.; Tukamoto, K.; Tomita, B. 2000. Application of liquefied wood to a new resin systemsynthesis and properties of liquefied wood/epoxy resins. Holzforschung 54(1): 93-100.

Kunaver, M.; Medved, S.; Cuk, N. 2010. Application of liquefied wood as a new particle board adhesive system. Bioresource Technology 101(4): 1361-1368.

Lee, W.; Lin, M. 2008. Preparation and application of polyurethane adhesives made from polyhydric alcohol liquefied Taiwan acacia and China fir. Journal of Applied Polymer science 109: 161-177.

Lin, R.; Sun, J.; Yue, C.; Wang, X.; Tu, D.; Gao, Z. 2014. Study on preparation and properties of phenol-formaldehyde-chinese fir liquefaction copolymer resin. Maderas. Ciencia y tecnología 16(2): 159174.

Mansouri, N.; Pizzi, A.; Salvado, J. 2007. Lignin-based wood panel adhesives without formaldehyde. Holz Roh Werkst 65: 65-70.

Martins, J.; Cruz Lopes, L.; Esteves B. 2013. Otimização da liquefação da madeira de Pinus pinaster com poliálcoois. (In Portuguese). Silva Lusitana 21: 177-185.

Pan, H.; Shupe, T. F.; Hse, C.Y. 2009. Characterization of novolac type liquefied. Eur J Wood Prod 67: 427-437.

Ugovsek, A.; Kariz, M.; Sernek, M. 2010. Bonding of beech wood with an adhesive mixture made of liquefied wood and phenolic resin, Hardwood Science and Technology. The $4^{\text {th }}$ Conference on Hardwood Research and Utilisation in Europe.

Xie, T.; Chen, F. 2005. Fast liquefaction of bagasse in ethylene carbonate and preparation of epoxy resin from liquefied product. Journal of Applied Polymer Science 98: 1961-1968.

Zhang, Q.; Zhao, G.; Jie, S. 2005. Liquefaction and product identification of main chemical compositions of wood in phenol. Forestry Studies in China 7(2): 31-37.

Zhang, Q.H.; Zhao, G.J.; Yu, L.L.; Jie S.J. 2007. Preparation of liquefied wood-based resins and their application in molding material. Forestry Studies in China 9(1): 51-56. 